\title{
ОСОБЕННОСТИ РАЗВИТИЯ УРОВНЯ ПРИТЯЗАНИЙ СТАРШИХ ПОДРОСТКОВ С НАРУШЕНИЕМ ЗРЕНИЯ
}

\section{THE DEVELOPMENTAL CHARACTERISTICS OF OLDER ADOLESCENTS' LEVEL OF ASPIRATION WITH VISUAL IMPAIRMENT}

A. Ulanova

S. Khaidov

Summary: The article is devoted to the study of the developmental characteristics of older adolescents' level of aspiration with visual impairments. There are diagnostic methods that allow to study the level of aspiration and such processes interrelated with it as self-esteem, motivational components and locus of control is resulted in this article. The article presents the results of the theoretical and empirical study of the level of aspiration of adolescents aged 14-15 with visual impairment. There are peculiarities of development of specific indicators revealed and their development trends determined.

Keywords: level of aspiration, older adolescence, visual impairment, need-motivational sphere, personality.

\section{Введение}

$\Pi$ роблема исследования уровня притязаний старших подростков с нарушением зрения на современном этапе остаётся достаточно острой и представляет особый интерес, поскольку возрастает количество детей с различными зрительными дефектами, оказывающими неблагоприятное воздействие на потребностно-мотивационную сферу, а именно на развитие уровня притязаний.

Исследования структуры и динамики формирования уровня притязаний важны для понимания личности. Уровень притязаний представляет собой личностный конструкт, имеющий значение уровня трудности цели, которую выбирает субъект в своей деятельности, и обусловленный взаимосвязью мотивационно-поведенческой и эмоционально-оценочной сфер [1].

Подростковый возраст - это особый этап развития личности, когда активно формируется способность строить жизненные планы, усиливается стремление к самоанализу и самосознанию. Интерес к собственной личности, к выявлению своих возможностей порождает у подростков потребность соответствовать не только требованиям окружающих, но и отвечать своим собственным запросам и притязаниям [9].
Уланова Анастасия Олеговна

Тульский государственный педагогический университет им. Л.Н. Толстого nastaulanova2000god@gmail.com

Хаидов Сергей Курбанович к.nсх.н., доцент, Тульский государственный педагогический университет им. Л.Н. Толстого

haidov@bk.ru

Аннотация: Данная статья посвящена изучению особенностей развития уровня притязаний старших подростков с нарушением зрения. Приведены диагностические методики, позволяющие изучить уровень притязаний и взаимосвязанные с ним процессы, такие как самооценка, мотивационные компоненты и локус контроля. Представлены результаты теоретического и эмпирического исследования уровня притязаний подростков 14-15 лет с нарушением зрения. Выявлены особенности развития отдельных показателей и определены тенденции их развития.

Ключевые слова: уровень притязаний, старший подростковый возраст, нарушение зрения, мотивационно-потребностная сфера, личность.

Неадекватность уровня притязаний приводит к расстройствам целеполагания, трудности реализации процесса достижения цели, снижению продуктивности деятельности и неадекватному оцениванию своих возможностей. Нарушение развития уровня притязаний старших подростков со зрительной патологией в дальнейшем будет затруднять их социальную адаптацию и реабилитацию.

Несмотря на увеличение в последнее время исследований, направленных на выявление личностных характеристик и особенностей самооценки подростков с нарушением зрения, проблема развития уровня притязаний детей данной категории изучена недостаточно. В связи с этим возрастает актуальность и необходимость исследования данной проблемы.

\section{ヘитературный обзор}

Особенности развития мотивационно-потребностной сферы подростков с нарушением зрения стали предметом научного исследования в работах таких отечественных и зарубежных авторов, как А.И. Суславичюс, Е.М. Украинская, А.Г. Литвак, Р.А. Курбанов, А.М. Виленская, О.В. Гордеева, Л. Пожар, Л.И. Солнцева, И.Г. Корнилова, Д. Джервис, Д. Татл и Н. Татл, И.Н. Никулина, А.А. Голикова $[2,3,5-7,10]$ и др.

Общая идея, которая звучит в исследованиях боль- 
шинства авторов, определяет сенсорную недостаточность как важнейший фактор изменений развития личности, проявляющийся в усложнении взаимодействия детей с окружающей средой, изменении их социальной позиции и затруднении социальной активности. В свою очередь это приводит к развитию нереалистичной самооценки и установлению неадекватных притязаний $[7,8,10]$.

Многими авторами высказывалась мысль о том, дети данной категории, как правило, склонны недооценивать свои способности или наоборот завышать имеющиеся возможности [4]. Это говорит о том, что уровень притязаний старших подростков с нарушением зрения чаще неадекватно занижен или завышен. Неадекватность уровня притязаний проявляется в следующих аспектах: 1) цели, выбираемые подростками, превосходят их реальные ресурсы, при этом они чаще сталкиваются с неудачами; 2) подросток ставит перед собой слишком лёгкие и достижимые цели, что мешает полноценной реализации своего потенциала и становлению личности.

В связи с этим подростков с нарушением зрения можно отнести к двум группам: хорошо адаптированные в обществе, чаще с завышенной самооценкой и уровнем притязаний; лица малоадаптированные или неадаптированные, имеющие заниженный уровень притязаний [11]. Неадекватность уровня притязаний и связанной с ним самооценки может свидетельствовать о неблагоприятном личностном развитии.

\section{Методы исследования}

Учитывая цели и задачи исследования, были выбраны следующие диагностические методики, которые позволяют изучить особенности развития уровня притязаний старших подростков с нарушением зрения:

1. Методика «Шкала Дембо-Рубинштейн» (Т.В. Дембо, С.Я. Рубинштейн, модификация А.М. Прихожан)

2. Методика «Моторная проба Шварцландера» (Й. Шварцландер)

3. Опросник «Оценка уровня притязаний» (В.К. Гербачевский)

4. Методика «Диагностика уровня субъективного контроля» (Дж. Роттер, адаптация Е.Ф. Бажина, С.А. Голынкиной, А.М. Эткинда).

Выбор этих методик обусловлен тем, что они позволяют учитывать зрительный дефект и индивидуальные особенности исследуемых. Данные методики предоставляют возможность исследовать уровень притязаний с различных сторон и взаимосвязи с другими составляющими личностной сферы.

Так методика «Шкала Дембо-Рубинштейн» позволяет изучить уровень притязаний через его взаимосвязь с самооценкой и анализ личностных качеств; методика «Моторная проба Шварцландера» диагностирует уровень притязаний с точки зрения его динамики, прослеживается влияние достижения и переживания успеха или неудачи в деятельности. Опросник «Оценка уровня притязаний» рассматривает уровень притязаний в контексте его связи с компонентами мотивационной структуры. Методика «Диагностика уровня субъективного контроля» позволяет исследовать характер контроля над разнообразными жизненными ситуациями, который в свою очередь определяет реалистичность притязаний личности.

В исследовании при качественном и количественном анализе использовалась статистическая программа SPSS 21. Применялся корреляционный анализ Спирмена, непараметрический критерий Мани-Уитни, описательная статистика.

\section{Ход исследования и его результаты}

Исследование проводилось на базе МБОУ «ЦО №29», г. Тула. В исследовании приняли участие 13 учащихся в возрасте 14-15 лет, из них 8 мальчиков и 5 девочек. Небольшая выборка исследуемых обусловлена тем, что дети данной категории обучаются в условиях интегрированного образования.

Анализ результатов исследования с помощью методов математической статистики и корреляционного анализа Спирмена показал наличие следующих связей.

Была выявлена значимая положительная связь между самооценкой и уровнем притязаний $(\mathrm{Cr}=0,906$; $\mathrm{p}=0,005)$. Это свидетельствует о том, что высокая оценка своих способностей и личностных качеств позволяет подросткам ставить цели более высокого уровня сложности. Также отмечается прямая связь между уровнем притязаний и мотивом самоуважения $(\mathrm{Cr}=0,836$; $\mathrm{p}=0,019)$ - иначе говоря, возрастание уровня притязаний влияет на повышение мотива самоуважения, который в экспериментальных условиях отражает притязания испытуемых и подразумевает осознание ими возможности совершать личностно - ценные действия.

Между показателями реалистичности и динамики уровня притязаний отмечается прямая связь $(\mathrm{Cr}=0,867$; $\mathrm{p}=0,012)$. Следовательно, установление реалистичного уровня притязаний позволяет подросткам адекватно выбирать цели в соответствии с достигнутыми результатами, то есть изменять и направлять процесс целеполагания.

Были выявлены обратные связи показателя значимости достигнутых результатов с такими показателями, как самооценка $(\mathrm{Cr}=-0,829 ; \mathrm{p}=0,021)$, уровень притязаний 
$(\mathrm{Cr}=-0,805 ; \mathrm{p}=0,029)$ и мотив самоуважения $(\mathrm{Cr}=-0,821$; $\mathrm{p}=0,023)$. Это говорит о том, что повышение личностной значимости результатов, получаемых в определенной деятельности, приводит к снижению самооценки исследуемых, к неадекватной постановке целей и нереалистичной оценке своей значимости.

Отрицательная связь между волевым усилием и инициативностью $(\mathrm{Cr}=-0,891 ; \mathrm{p}=0,007)$ указывает на наличие следующей закономерности: волевое усилие требует от детей высоких энергетических затрат, в связи с этим снижается их инициативность и активность.

Методы математической обработки по непараметрическому критерию Манна-Уитни не выявили статистически значимых различий между мальчиками и девочками, но тем не менее существуют количественные различия (Таблица 1).

Как видно из Таблицы 1, в общей выборке исследуемых самооценка имеет средний уровень с тенденцией к адекватно высоким значениям. Самооценка мальчиков имеет средний уровень, у девочек же отмечается высокий уровень и большая тенденция к развитию. Однако стоит отметить, что полученные средние значения самооценки по обеим выборкам обусловлены крайними проявлениями низких и высоких значений у всех исследуемых, что подтверждается и стандартным отклонением.

Анализ результатов показал, что уровень притязаний в общей выборке имеет высокие значения. При этом как у мальчиков, так и у девочек наблюдается тенденция к нереалистичным, очень высоким показателям.

Со стороны динамики уровня притязаний отмечается умеренность проявлений, свидетельствующая об отсутствии у испытуемых готовности перейти к целям более высокого уровня сложности и стремления достичь лучших результатов. В то же время динамика уровня притязаний более адекватна у мальчиков, поскольку их количественные значения находятся на границе с нормой и имеют тенденцию к реалистично высоким значениям.

В общей выборке компоненты мотивационный структуры имеют стабильно средний уровень, при этом мотив самоуважения характеризуется тенденцией к высоким значениям. Это может свидетельствовать о том, что подростки стремятся повысить свою значимость и ценность, при этом не изменяя своих действий. У девочек отмечается неравномерность проявлений компонентов мотивационной структуры. Состязательный мотив у них приближен к высокому уровню, в то время как волевое усилие проявляется на низком уровне, а инициативность - на границах среднего.

Локус контроля у девочек и мальчиков имеет значения экстернальности. Это ещё раз подтверждает тот факт, что для подростков на первый план выходит не столько значимость достижения цели, сколько факт одобрения или осуждения сделанного.

\section{Выво $\Delta ы$}

Таким образом, мы видим, что большинство исследуемых показателей в общей выборке имеют средние значения и характеризуются тенденцией к увеличению. При этом показатель реалистичности уровня притязаний отмечается на высоком уровне у всех испытуемых независимо от пола. У мальчиков наблюдаются большие тенденции к положительной динамике уровня притязаний и развитию мотивационных компонентов в отличие от девочек. В связи с этим можно говорить о том, что нарушения зрения в большей степени оказывают воздействие на личностное развитие лиц женского пола.

Таблица 1

\begin{tabular}{|c|c|c|c|c|c|c|}
\hline \multirow{2}{*}{ Показатели } & \multicolumn{2}{|c|}{ Общая выборка } & \multicolumn{2}{|c|}{ Мальчики } & \multicolumn{2}{|c|}{ Девочки } \\
\hline & Среднее & Стд. отклонение & Среднее & Стд. отклонение & Среднее & Стд. отклонение \\
\hline Самооценка & 57,4286 & 34,43766 & 55,2000 & 32,75210 & 63,0000 & 52,32590 \\
\hline $\begin{array}{l}\text { Уровень притязаний } \\
\text { Дембо-Рубинштейн }\end{array}$ & 85,5714 & 19,76408 & 85,0000 & 22,36068 & 87,0000 & 18,38478 \\
\hline Уровень притязаний & 2,5143 & 3,28757 & 2,1800 & 1,86333 & 3,3500 & 7,00036 \\
\hline Мотив самоуважения & 16,7143 & 4,42396 & 15,8000 & 5,01996 & 19,0000 & 1,41421 \\
\hline $\begin{array}{l}\text { Значимость достигнутых } \\
\text { результатов }\end{array}$ & 11,1429 & 3,67099 & 11,2000 & 4,43847 & 11,0000 & 1,41421 \\
\hline Состязательный мотив & 14,8571 & 2,79455 & 13,4000 & 1,51658 & 18,5000 & ,70711 \\
\hline Волевое усилие & 12,8571 & 4,33699 & 14,2000 & 2,28035 & 9,5000 & 7,77817 \\
\hline Инициативность & 12,7143 & 3,14718 & 13,2000 & 1,92354 & 11,5000 & 6,36396 \\
\hline Локус-контроль & 4,5000 & 1,00000 & 4,4000 & 1,08397 & 4,7500 & 1,06066 \\
\hline
\end{tabular}


Представленные результаты позволяют сделать вывод о том, что зрительная патология в совокупности с сенситивным подростковым периодом влияет на неравномерное развитие мотивационно-потребностной сферы. Притязания подростков с нарушением зрения не соотносятся с их имеющимися возможностями, прило- женными усилиями и совершаемыми действиями. Отмечаемые тенденции к увеличению и развитию позволяют определить потенциальные направления реабилитации и коррекционного воздействия, которые заключаются в становлении реалистичного уровня притязаний, адекватной самооценки и развитию навыков целеполагания.

\section{ЛИТЕРАТУРА}

1. Бороздина Л.В. Уровень притязаний: классические и современные исследования. М.: Акрополь, 2011. 322 с.

2. Виленская, А.М. Некоторые особенности личности старших классов школ для слепых детей // Х научная сессия по дефектологии. М., 1990. С. 12-13.

3. Голикова А.А., Кучинский В.Ф. Самоотношение подростков с различной степенью выраженности нарушений зрения // Современные проблемы науки и образования. 2015. №4. С. 44

4. Зябкина И.В., Рябуха К.С. Особенности самооценки и уровня притязаний у слабовидящих подростков // Ученые записки Крымского инженерно-педагогического университета. 2017. № 4 (10). С. 70-74.

5. Курбанов, Р.А. Особенности общения слепых детей в условиях совместной деятельности // Современные исследования по проблемам учебной и трудовой деятельности аномальных детей: тезисы доклада. Х научная сессия по дефектологии. М., 1990. С. 38.

6. Литвак А.Г. Психология слепых и слабовидящих: учеб. пособие / А.Г. Литвак ; Рос. гос. пед. ун-т им. А.И. Герцена. - СПб.: Изд-во РГПУ, 1998. - 271 с.

7. Пожар Л. Психология аномальных детей и подростков - патопсихология. М.: Воронеж. 1996. 128 с.

8. Прилепская Т.Н. Особенности самооценки и уровня притязаний у глухих и слышащих школьников // Дефектология 1989, № 5. - С. 26 - 38

9. Райс Ф., Долджин К. Психология подросткового и юношеского возраста. СПб.: Питер, 2012. 816 с.

10. Солнцева, Л.И. Тифлопсихология детства. М.: Полиграф сервис, 2000. 250 с.

11. Шалагина Т.С. Реабилитация слепых от рождения // Проблемы социальной реабилитации слепых. - М.: ВОС, 1990. - С. $22-23$

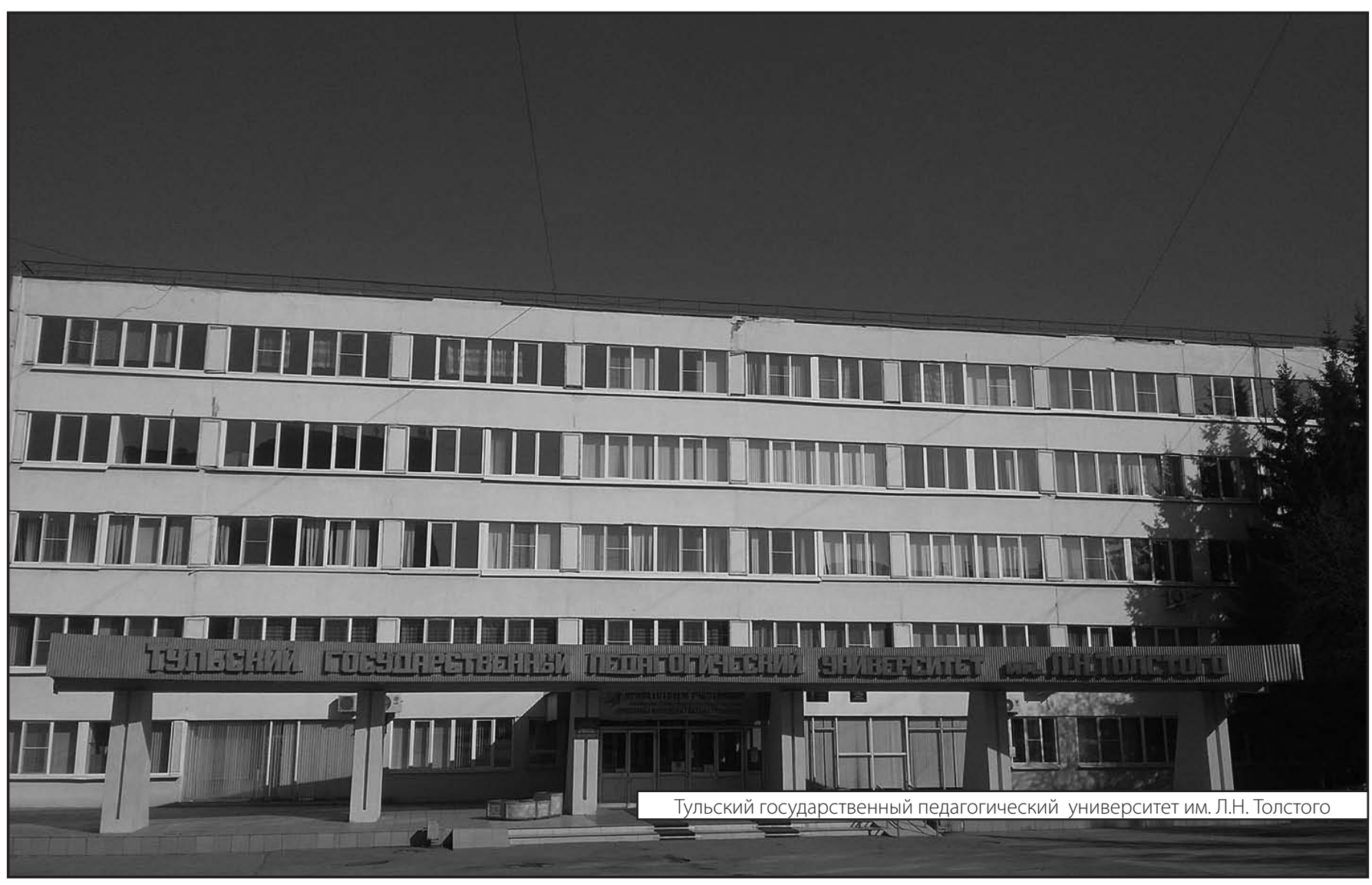

